\title{
Inflation Regimes and Inflation Expectations
}

\author{
Joseph E. Gagnon
}

This paper examines the formation of expectations about future inflation over long horizons. A key issue that agents must confront is the possibility that the economic policy frameworkespecially the monetary policy regime-could change at some future date. Agents are likely to base inferences about possible future regimes on experience over many years and decades past. This aspect of expectations formation may explain why inflation premiums in long-term bond yields are higher in countries with a long history of high inflation. (JEL E52, E61, G12)

Federal Reserve Bank of St. Louis Review, May/June 2008, 90(3, Part 2), pp. 229-43.

"The further backward you look, the further forward you can see."

$$
\text { —Winston Churchill }
$$

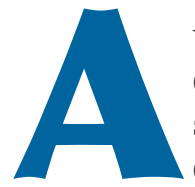
verage inflation rates in industrial countries have fallen substantially since the 1980s. In several cases, countries that experienced higher inflation than the industrial-country average during the 1970s and 1980s achieved lower-thanaverage inflation in the 1990s. Bond yields in industrial countries have generally fallen by more than inflation rates, reflecting increased credibility of anti-inflationary policies. But the countries with the lowest inflation rates in recent years have not necessarily been those with the lowest bond yields. In particular, countries with a long history of higher inflation continue to have higher bond yields.

To provide concrete examples, Table 1 shows two bilateral comparisons: the United States versus Canada and Australia versus New Zealand. Average inflation was lower in Canada than in the United States in both the 1990s and the current decade. Indeed, Canadian inflation was lower than U.S. inflation in 13 of the 16 years since 1991. Despite this consistent record of lower inflation, the yield on 10-year government bonds in Canada was higher than comparable yields in the United States in both periods. ${ }^{1}$ Similarly, the inflation rate was lower in New Zealand than in Australia for 14 of the past 16 years. New Zealand bond yields were slightly lower than Australian yields in the 1990s, but by less than the difference in inflation rates, and they have been higher than Australian yields in the current decade, despite continued lower inflation.

One explanation for these findings is that long-term inflation expectations depend on a long history of past inflation-more than just the past 5 or 10 years. Indeed, during the 1980s, inflation averaged 5.8 percent in Canada versus 4.6 percent in the United States and 10.2 percent in

1 The higher Canadian bond yields in this decade are all the more surprising in light of the fiscal surplus in Canada and the fiscal deficit in the United States.

\footnotetext{
Joseph E. Gagnon is associate director of the Division of International Finance at the Board of Governors of the Federal Reserve System. An earlier version of this paper was circulated as Research Discussion Paper 9701 of the Reserve Bank of Australia and as International Finance Discussion Paper 581 of the Federal Reserve Board. The initial work was completed when the author was visiting the Reserve Bank of Australia in 1997. The author thanks David Bowman, Gordon DeBrouwer, Jeff Dominitz, Jon Faust, David Gruen, Dale Henderson, Andrew Levin, Jenny Wilkinson, and a referee for their helpful comments.

(C) 2008, The Federal Reserve Bank of St. Louis. The views expressed in this article are those of the author(s) and do not necessarily reflect the views of the Federal Reserve System, the Board of Governors, the regional Federal Reserve Banks, or the Reserve Bank of Australia. Articles may be reprinted, reproduced, published, distributed, displayed, and transmitted in their entirety if copyright notice, author name(s), and full citation are included. Abstracts, synopses, and other derivative works may be made only with prior written permission of the Federal Reserve Bank of St. Louis.
} 


\section{Gagnon}

\section{Table 1}

\section{Average Inflation Rates and Bond Yields}

\begin{tabular}{|c|c|c|c|c|c|c|}
\hline & \multicolumn{2}{|c|}{ 1981-90 } & \multicolumn{2}{|c|}{ 1991-2000 } & \multicolumn{2}{|c|}{ 2001-06 } \\
\hline & Inflation & Yield & Inflation & Yield & Inflation & Yield \\
\hline United States & 4.6 & 10.3 & 2.8 & 6.4 & 2.7 & 4.5 \\
\hline Canada & 5.8 & 11.6 & 2.0 & 7.4 & 2.3 & 5.1 \\
\hline Australia & 7.8 & 13.6 & 2.2 & 7.8 & 3.1 & 5.6 \\
\hline New Zealand & 10.2 & 14.0 & 1.7 & 7.5 & 2.6 & 6.0 \\
\hline
\end{tabular}

SOURCE: Consumer price inflation rates and long-term government bond yields were obtained from IMF International Financial Statistics.

New Zealand versus 7.8 percent in Australia. A similar pattern (not shown) also characterizes the 1970s. In each case, the country with lower recent inflation experienced higher inflation over a long period in the past. The effect of past inflation over a long horizon may also explain the higher bond yields in Australia and New Zealand versus the United States and Canada. ${ }^{2}$

More generally, there is evidence documented by Gagnon (1996) that nominal long-term interest rates are strongly correlated with both recent inflation and past inflation over a long horizon. This correlation holds both across countries and within countries over time. One explanation for this correlation is that long-term inflation expectations are influenced by a long history of past inflation.

This article develops a theoretical framework to explain these empirical findings. The basic idea is that at least since the collapse of the gold standard in the 1930s, the policy regimes of most central banks have periodically changed. Regime changes may be associated with changes in the central bank governor or political party in power, depending on the institutional independence of the central bank. Other factors may give rise to regime changes: Evolving theories about economic behavior may lead to new views on the optimal

2 Another explanation for different nominal long-term interest rates is that real long-term interest rates may differ across countries. Market forces should arbitrage away such differences over time as long as capital and goods markets are open. Moreover, as discussed later, direct evidence on the inflation component of bond yields supports the conclusions of this paper. conduct of monetary policy. Or, extreme social or economic shocks may necessitate a persistent shift in monetary policy. However, in general, it is not useful to think of the regime changing with every shock. Instead, regimes are viewed as implicit or explicit rules governing the behavior of monetary policy in response to ordinary shocks.

One important outcome of different monetary regimes is different average inflation rates across regimes. When agents consider expected inflation over a long future horizon, they must factor-in the possibility that the current regime will not survive over the horizon in question. Recent inflation rates may provide a good forecast of future inflation rates if the current regime survives, but they may not provide a good forecast if the current regime is replaced. To factor-in the effect of a potential new regime, agents may base their forecasts on their experience of past monetary regimes over a long horizon.

For instance, in 1989 the Reserve Bank of New Zealand adopted a central target of 1 percent inflation, which was lower than the inflation rate in 39 of the previous 40 years. It is likely that any agent considering the possibility of a new inflation regime in the future would expect the new regime to have average inflation greater than 1 percent. Even if agents believed that the Reserve Bank would achieve its target of 1 percent inflation in the current regime, they would have to factor the possibility of a change to a higherinflation regime into their expectations, thereby raising expected future inflation above 1 percent. The importance of regime changes for expecta- 
tions of future inflation was borne out by subsequent political developments in New Zealand, which led to an increase in the center of the inflation target range from 1 percent to 1.5 percent and then to 2 percent.

In addition to explaining long-run inflation expectations in bond markets, a model with regime changes can explain the peculiar timeseries properties of actual inflation over the postwar period. For most industrial countries, it is difficult to reject a unit root in the inflation rate. Yet, recent studies have found some evidence of weak mean reversion of inflation rates over long horizons. It is well known that structural breaks in an otherwise stationary series can induce apparent unit roots into the series. If inflation has undergone a small number of regime shifts in the postwar period, it would be difficult to reject a unit root. However, if the regime shifts themselves were around a constant average inflation rate, one would expect to find some evidence of mean reversion in inflation. Moreover, within relatively long-lasting regimes, it should be possible to reject a unit root, which may explain the apparent stationarity of inflation over certain subsamples.

Finally, the possibility of regime shifts leads to highly asymmetric distributions of future inflation rates. The asymmetric distribution of future inflation may explain the asymmetric distribution of survey responses on future inflation expectations. Moreover, the asymmetric distribution of future inflation may explain the frequently large discrepancies between surveys of inflation expectations and implied inflation expectations in bond yields. If survey respondents report the most likely outcome (the statistical mode) and bondholders care about the average outcome (the statistical mean), then the discrepancy between different measures of inflation expectations would be resolved.

\section{LITERATURE REVIEW}

\section{Empirical Models of Inflation}

Empirical analyses of the long-run properties of inflation rates have often occurred in the context of the real interest rate literature. See, for example, Rose (1988) and Mishkin (1992). Using data from the entire postwar period, one cannot reject a unit root in inflation for most industrial countries using standard augmented DickeyFuller tests. However, for many countries, one can reject nonstationarity of the inflation rate in certain subsamples.

Hassler and Wolters (1995) and Baillie, Chung, and Tieslau (1996) use the Phillips-Perron test and the KPSS test on postwar monthly inflation rates and reject both a unit root and stationarity for several countries. To reconcile these conflicting findings, they turn to models with "fractional integration" and find that they are strongly supported by the data. Fractional integration allows for slow mean reversion that does not decay as rapidly as the asymptotically exponential pattern associated with standard autoregressive moving-average models. This slow mean reversion is termed "long memory."

Other researchers have sought to explain the apparent nonstationarity of inflation as the result of regime shifts in the mean and variability of the inflation rate. Chapman and Ogaki (1993), Hostland (1995), Bai and Perron (1998), and Levin and Piger (2002) find significant evidence of regime shifts in inflation in several industrial countries, including the United States. Evans and Lewis (1995), Ricketts and Rose (1995), and Simon (1996) estimate Markov-switching models for inflation in the G-7 countries and Australia. At least two regimes are statistically significant in all countries except Germany.

Occasional shifts in the inflation regime are more economically interpretable than fractional integration. Moreover, if there are only a small number of regimes that cycle back and forth, or if the regime-generating process is stationary, simple models of inflation will appear to have long memory, which is consistent with the fractional integration literature.

\section{Evidence from Bond Markets}

Instead of modeling the inflation process, a more direct way to learn about long-run inflation expectations is to examine the inflation premiums in long-term bond markets. Fuhrer (1996) shows that the pure expectations theory of the term 


\section{Gagnon}

structure fits better when one allows structural breaks in the Fed reaction function, especially the implicit inflation target. Gagnon (1996) shows that the inflation premium in long-term interest rates is more closely correlated with a long backward average of inflation than a short backward average, implying that there is long memory in long-run inflation expectations and/or the inflation risk premium.

Focusing directly on countries that announced explicit inflation targets, Ammer and Freeman (1995) and Freeman and Willis (1995) provide evidence that announced inflation targets were not fully credible in the first few years after adoption, where credibility is defined as obtaining long-term inflation expectations equal to the official target for inflation. I present updated evidence on credibility of inflation policies in a later section of this paper.

\section{MODELS OF INFLATION REGIMES}

\section{Complete Information}

I begin with a model in which agents are fully informed. They know when a regime change has occurred. They know the inflation target of the current regime. They know the probability with which the current regime will end in the next period. And they know the probability distribution of the inflation target across future regimes. (I will relax some of these assumptions later.)

$$
\begin{gathered}
\pi_{t}=\Pi_{t-1}+\varepsilon_{t} \\
\Pi_{t}=\left(1-\theta_{t}\right) \Pi_{t-1}+\theta_{t} \eta_{t}
\end{gathered}
$$

The inflation rate, $\pi$, in each period is given by the inflation target, $\Pi$, effective in the previous period plus a random error, $\varepsilon$. This lag reflects the conventional monetary transmission lag of roughly one year. The word "target" is used loosely to mean the expected inflation rate within a given regime. It does not necessarily imply that the central bank is officially or unofficially aiming for this inflation rate, only that this inflation rate is the expected average outcome of its policies. More generally, one might expect the variability and persistence of the temporary shock, $\varepsilon$, to be different across regimes. However, such an empirically realistic extension would add complexity to the model without altering the basic theoretical conclusion.

A regime shift $(\theta=1)$ occurs with probability $q$. With probability $1-q$ there is no regime shift $(\theta=0)$. The probability of a regime shift in each period determines the average length of regimes. The expected length of a regime is $1 / q$ periods. An empirically reasonable range for inflation regimes is between 2 and 20 years, implying a value of $q$ between 0.05 and 0.5 . New inflation targets, $\eta$, are drawn from a normal distribution with mean $m$ and standard deviation $\kappa$.

This specification of the regime-shifting mechanism is silent on the forces that end existing regimes and give rise to new regimes. One interpretation is that different central bank governors have different objectives with regard to the level and variability of inflation and other economic variables. These differences are not fully observable prior to the appointment of a new governor. The term of each governor is random and depends on both personal factors and the struggle of partisan politics. Alternatively, inflation regimes may be seen as the outcome of broader social and political forces that are manifested in opinion polls, public debates, and election results. Still another possibility is that regime shifts are triggered by certain large and persistent shocks, such as energy supply shocks.

One important feature of the models developed in this paper is that the regime-generating process is stationary. In the broad global and historical context, this assumption is reasonable, because inflation rates tend to be bounded between a small negative and a large positive number. Hyperinflations are at most sporadic and not persistent, while hyperdeflations have never happened. However, within these bounds it is conceivable that the regime-generating process has drifted over time. Such a drift may be the result of demographic or technological forces that operate on a time scale much larger than that of monetary policy regimes. Or one may view the switch to fiat money standards this past century as the beginning of a new era in which 
central banks have had to learn about society's inflation preferences by trial and error. In such a world, one would expect the mean of inflation regimes to drift as central bank learning proceeds. In either case, inflation regimes would appear stationary over a sufficiently long time span, but may appear nonstationary in certain finite samples.

I begin this analysis by considering the formation of inflationary expectations in this model. Expected inflation over the next period is simply given by the current inflation target as shown in equation (3). Expected inflation in subsequent periods is a weighted average of the current inflation target and the expected value of future inflation targets, as shown by equations (4) and (5). The farther ahead one looks, the more likely there will be at least one regime shift and the greater the weight attached to the expected value of future inflation targets, $\mu$.

$$
\begin{gathered}
E_{t} \pi_{t+1}=\Pi_{t} \\
E_{t} \pi_{t+2}=(1-q) \Pi_{t}+q \mu \\
E_{t} \pi_{t+1+i}= \\
(1-q)^{i} \Pi_{t}+q\left(\sum_{j=1}^{i}(1-q)^{j-1}\right) \mu \quad i=1, \ldots, \infty
\end{gathered}
$$

One important property of this model is that the probability density of future inflation is not symmetric if there is a possibility that a regime change may affect the inflation rate in the period in question. The probability density of inflation one period ahead is symmetric because any regime shift that may occur next period will not affect inflation until the following period. For oneperiod-ahead inflation, the probability density is simply the normal density with mean equal to the current inflation target and variance equal to that of the temporary shock (equation (6)). The notation $f_{\varepsilon}(x)$ refers to the probability density of the variable $\varepsilon$ evaluated at the value $x$. For example, if $\sigma=1, f_{\varepsilon}(0)=0.4$ because $\varepsilon$ has a standard normal distribution and the standard normal density at zero is 0.4 .
(6)

$$
f_{\pi_{t+1}}(x)=f_{\varepsilon}\left(x-\Pi_{t}\right)
$$

(7)

$$
\begin{aligned}
& f_{\pi_{t+2}}(x)=(1-q) f_{\varepsilon}\left(x-\Pi_{t}\right)+q \int_{-\infty}^{\infty} f_{\eta}(x-\varepsilon) f_{\varepsilon}(\varepsilon) d \varepsilon \\
& f_{\pi_{t+1+i}}(x)= \\
& (1-q)^{i} f_{\varepsilon}\left(x-\Pi_{t}\right)+ \\
& q\left(\sum_{j=1}^{i}(1-q)^{j-1}\right) \int_{-\infty}^{\infty} f_{\eta}(x-\varepsilon) f_{\varepsilon}(\varepsilon) d \varepsilon \quad i=1, \ldots, \infty
\end{aligned}
$$$$
\text { (8) }
$$

If we look two periods ahead, the probability density of inflation takes on a two-part form. The first term in equation (7) states that if the current regime survives next period (with probability $1-q$ ), the probability density of inflation two periods ahead is the same as for one period ahead. The second term in equation (7) states that if the current regime is replaced next period (with probability $q$ ), the probability density of inflation in subsequent periods is a convolution of two densities. The first density under the integral is the density of inflation targets across regimes, and the second density is the density of inflation rates within a regime.

If we look ahead $1+i$ periods, the probability of remaining in the current regime declines to $(1-q)^{i}$ and the probability of moving to a new regime increases accordingly. It is possible that there may be one or more regime shifts over this horizon, but the probability density of future inflation is independent of the number of regime shifts that may occur. ${ }^{3}$

I now consider an example to illustrate the properties of this model. The parameters are adapted from the three-state Markov process estimates of Ricketts and Rose (1995; RR) for Canada over the period 1954-93. RR assume that inflation cycles among three different regimes, with mean inflation rates of $1.5,4.5$, and 9 percent. ${ }^{4}$ Translating these estimates into the model

3 This property would not hold true if there were dependence across regimes.

4 RR allow different serial correlations and variances of inflation in different regimes. In the high-inflation regime they impose a unit root on the inflation rate, which is not rejected by the data. With a unit root the population mean is undefined, but the sample mean is 9 percent. 


\section{Figure 1}

\section{Model 1}

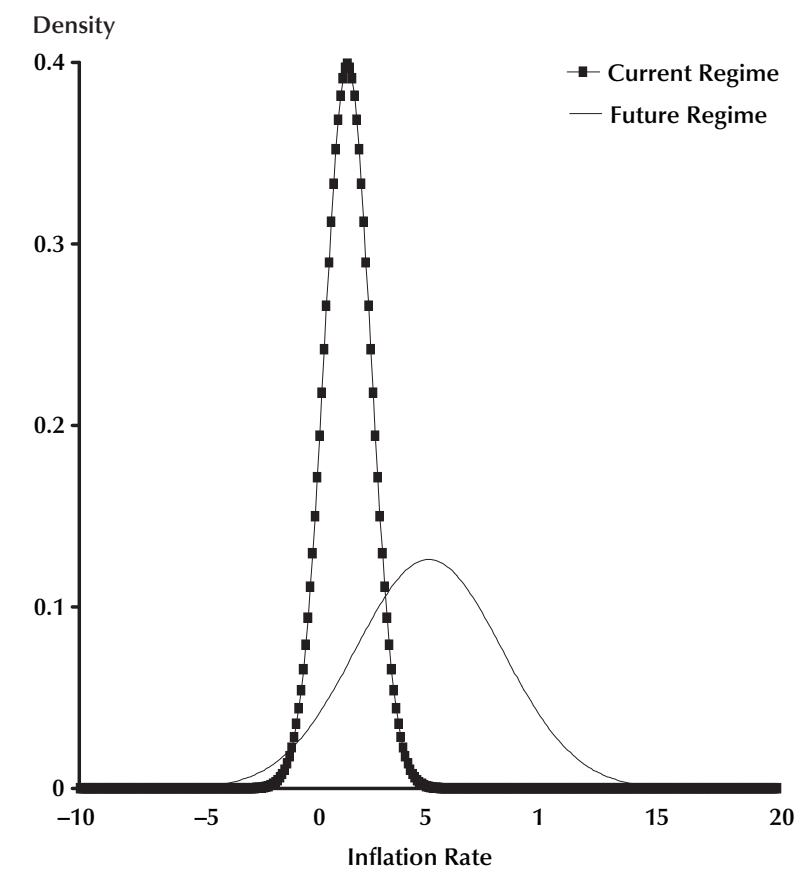

of this section implies a mean inflation rate across regimes of 5 percent $(\mu=5)$ with a standard deviation of 3 percent $(\kappa=3)$. (The average inflation rate over this sample is also 5 percent.) The probability of entering a new regime is 30 percent per year $(q=0.3) .{ }^{5}$ At the end of their sample, Canada was in the low-inflation regime $(\Pi=1.5)$. The standard deviation of inflation in the low-inflation regime is 1 percent, and this estimate is adopted for every regime in the model $(\sigma=1)$.

Figure 1 displays the probability densities of inflation under the current regime and under the assumption of a regime shift without any information on the inflation target in the new regime. Figure 2 displays the probability densities for inflation at different periods in the future. These densities are weighted averages of the two densities in Figure 1, with the weight on the regimeshift density increasing with the distance into

5 RR allow different probabilities of a regime shift, depending on the regime. For Canada, the probability of exiting a regime is close to 0.3 for each of the three regimes.

\section{Figure 2}

\section{Model 1}

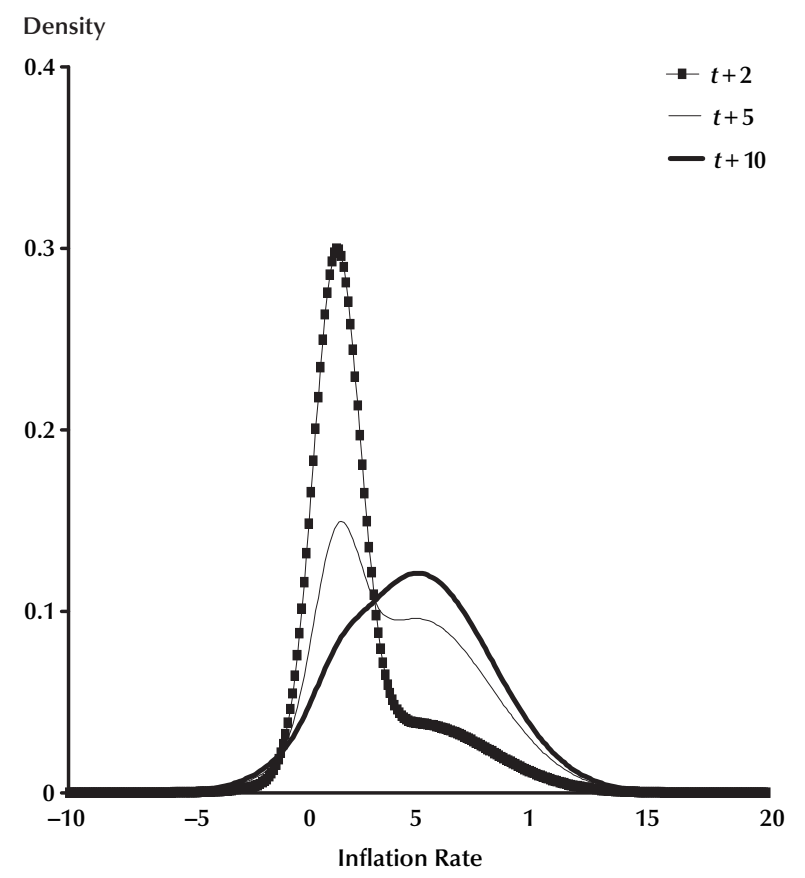

the future. Clearly, the weighting of these two densities-each of which is symmetric-leads to a highly asymmetric density for future inflation over certain horizons.

Table 2 displays the mean, median, and mode of inflation from 1 to 10 periods ahead under Model 1 . The asymmetry, as measured by the difference between the mean and the median, grows quickly and peaks in period $t+3$ before declining slowly over longer horizons. In period $t+10$ the density is quite close to the future regime density in Figure 1, which is symmetric. The density becomes bimodal in periods $t+4$ through $t+9$, with the second peak overtaking the first peak in period $t+8$. Over the entire 10-year period, the average of the mean inflation rates is 3.9 percent, the average of the medians is 3.5 percent, and the average of the modes is 2.7 percent.

\section{Learning about the Current Regime}

Of the four informational assumptions described at the beginning of the previous sub- 
section, the most realistic are that agents know when there has been a regime change and that they know the probability of a regime change in any given period. Regime changes are likely to be associated with observable events such as a change in the party or individual in control of the central bank, an announcement by the central bank indicating that a new policy has been adopted, or a major economic or social shock such as a war. The probability of a regime change is given by the institutional structure of government and the randomness of individual career decisions and lifespans. It does not seem unreasonable to assume that agents understand this process well, or at least that their beliefs about it are not changing over time.

The first assumption that I relax is the assumption that agents know any new target inflation rate immediately. Instead, I assume that agents learn about the current regime by observing the inflation rates that occur. During the period in which a regime shift occurs, the best any agent can do is to expect future inflation to be equal to the mean across regimes, $\mu$. (See equation (9).) The probability density is given by the convolution of the target density and the density of deviations from target, shown in equation (10).

$$
\begin{gathered}
E_{t} \pi_{t+i}=\mu \quad i=1, \ldots, \infty \\
f_{t, \pi_{t+i}}(x)=\int_{-\infty}^{\infty} f_{\eta}(x-\varepsilon) f_{\varepsilon}(\varepsilon) d \varepsilon \quad i=1, \ldots, \infty
\end{gathered}
$$

In the following period, an inflation rate is observed. Assuming that there is no regime change, the optimal learning procedure is to use Bayes's rule to update the probability density of future inflation under the assumption that the current regime continues. The prior density is given by equation (10). Equation (12) displays Bayes's rule, which uses the prior density combined with observed information on inflation in the current regime to determine the conditional probability density of future inflation under the assumption that the current regime survives. Because inflation one period ahead is not affected by any future regime change, its expected value

\begin{tabular}{|c|c|c|c|}
\hline \multicolumn{4}{|c|}{$\begin{array}{l}\text { Asymmetric Distribution of Futu } \\
\text { Rates: Model } \mathbf{1} \\
\Pi_{t}=1.5, \sigma=1, \mu=5, \kappa=3, q=0.3\end{array}$} \\
\hline Date & Mean & Median & Mode \\
\hline$t+1$ & 1.5 & 1.5 & 1.5 \\
\hline$t+2$ & 2.5 & 1.9 & 1.5 \\
\hline$t+3$ & 3.3 & 2.4 & 1.6 \\
\hline$t+4$ & 3.8 & 3.1 & 1.6 \\
\hline$t+5$ & 4.2 & 3.6 & 1.7 \\
\hline$t+6$ & 4.4 & 4.1 & 1.8 \\
\hline$t+7$ & 4.6 & 4.5 & 2.0 \\
\hline$t+8$ & 4.7 & 4.6 & 5.0 \\
\hline$t+9$ & 4.8 & 4.7 & 5.0 \\
\hline$t+10$ & 4.9 & 4.8 & 5.0 \\
\hline Average & 3.9 & 3.5 & 2.7 \\
\hline
\end{tabular}

\section{Table 2}

is given by the standard formula for the expectation of a continuously distributed random variable displayed in equation (11) using the density defined by equation (12).

$$
E_{t+1} \pi_{t+2}=\int_{-\infty}^{\infty} x f_{t+1, \pi_{t+2}}(x) d x
$$

$$
\begin{aligned}
& f_{t+1, \pi_{t+2}}(x)= \\
& \frac{\int_{-\infty}^{\infty} f_{\eta}(x-\varepsilon) f_{\varepsilon}(\varepsilon) f_{\varepsilon}\left(\pi_{t+1}-x+\varepsilon\right) d \varepsilon}{\int_{-\infty}^{\infty} \int_{-\infty}^{\infty} f_{\eta}(y-\varepsilon) f_{\varepsilon}(\varepsilon) f_{\varepsilon}\left(\pi_{t+1}-y+\varepsilon\right) d \varepsilon d y}
\end{aligned}
$$

Once the current regime ends, the distribution of future inflation reverts to its prior distribution (equation (10)). Thus, the probability density of inflation more than one period ahead takes the compound form presented in equation (14). In all periods beyond $t+2$, the probability density of inflation is equal to the probability of no regime change times the density for period $t+2$ plus the probability of a regime change times the prior density of inflation under an unknown regime. The expected value of inflation in periods beyond $t+2$ (equation (13)) takes a compound form parallel to equation (14). Note that the expected value of inflation under the prior density is $\mu$, the average inflation target across regimes. 


\section{Figure 3}

\section{Model 2}

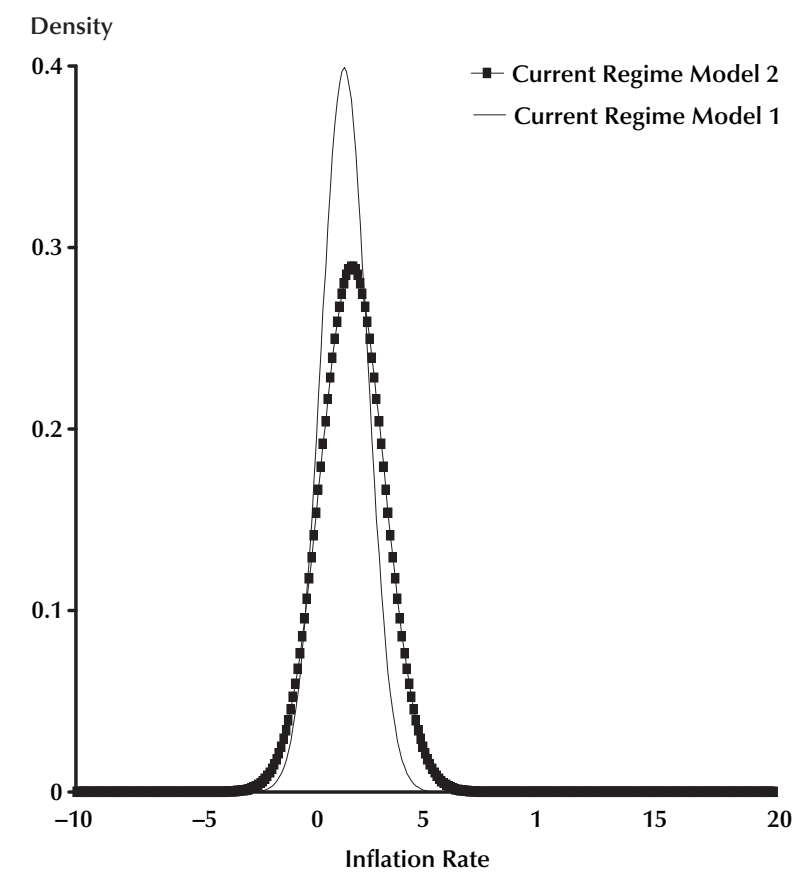

(13)

$$
\begin{aligned}
& E_{t+1} \pi_{t+2+i}= \\
& (1-q)^{i} E_{t+1} \pi_{t+2}+q \sum_{j=1}^{i}(1-q)^{j-1} \mu \quad i=1, \ldots, \infty \\
& \quad f_{t+1, \pi_{t+2+i}}(x)= \\
& \quad(1-q)^{i} f_{t+1, \pi_{t+2}}(x)+ \\
& q \sum_{j=1}^{i}(1-q)^{j-1} f_{t, \pi_{t+1}}(x) \quad i=1, \ldots, \infty
\end{aligned}
$$

After observing inflation in period $t+2$, the conditional density of inflation in period $t+3$ is given by Bayes's rule using the prior density (equation (10)) and two pieces of information, $\pi_{t+1}$ and $\pi_{t+2}$. (This density is not shown.) As more periods of inflation are observed without a regime shift, the influence of the prior density diminishes and the conditional density of inflation approaches that of the case in which the current regime target inflation rate is known.

\section{Figure 4}

\section{Model 2}

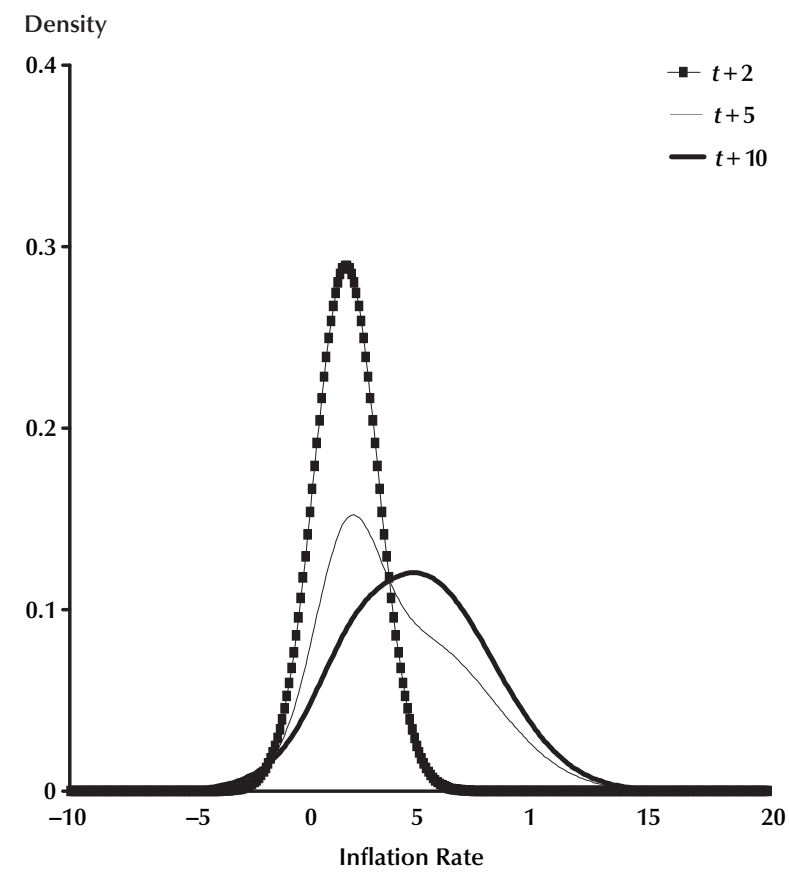

I now consider an example to illustrate the properties of this model. As in the previous section, suppose that the mean inflation target across regimes is 5 percent, with a standard deviation of 3 percent, and that the probability of a new regime is 0.3 per period. Suppose that within a regime, the standard deviation of inflation around its target is 1 percent and the current inflation target is 1.5 percent. If a regime shift occurs in the current period, the conditional density of future inflation in every period is given simply by the density under the assumption of a future regime shift, as shown in Figure 1.

If a regime shift occurred last period and the regime survives in the current period, the distribution of next period's inflation depends on the current observation of inflation. If we assume that current inflation is 1.5 (the current inflation target), Figure 3 displays the probability density of inflation next period. For comparison, the density assuming complete knowledge of the current 
regime is also plotted. Note that the density with incomplete knowledge is more diffuse than that assuming complete knowledge. Figure 4 displays the probability densities for inflation at various periods in the future. These densities are weighted averages of the density in Figure 3 and the density assuming an unknown regime shift (shown in Figure 1). Once again, the weighting of these two densities-each of which is symmetric-leads to an asymmetric density for future inflation.

Table 3, which pertains to Model 2, displays the mean, median, and mode of inflation from 1 to 10 periods ahead, conditional on observing inflation in period $t+1$ after a regime shift in period $t$. The growing asymmetry is readily apparent, but not as extreme as in the case of complete knowledge of the current regime.

\section{Learning about Future Regimes}

The other assumption that I relax is the assumption that agents know the distribution of target inflation rates across future regimes. To simplify the analysis, I return to the assumption that agents know the current and past inflation targets.

In this model, agents must estimate the mean and standard deviation of inflation targets across regimes using data on past regimes. Each time a new regime occurs, agents update their estimates of the mean and standard deviation. Expected inflation in the next period is simply the current inflation target, shown in equation (15). Expected inflation more than one period ahead is a weighted average of the current inflation target and the average of current and past inflation targets. (See equation (16).) Because inflation regimes typically last for more than one period, the second term in equation (16) is an average computed using the first year of each regime, denoted by the set $\left\{R_{N}\right\}$, which contains $N$ elements, where $N$ is the number of regimes. By the law of large numbers, when $N$ is large, the right-hand side of equation (16) approaches equality with the right-hand sides of equations (2) and (3). In other words, when there have been many regimes in the past, agents can estimate the true mean of future inflation targets quite accurately.

\section{Table 3}

\begin{tabular}{|c|c|c|c|}
\hline \multicolumn{4}{|c|}{$\begin{array}{l}\text { Asymmetric Distribution of Futu } \\
\text { Rates: } \text { Model } 2 \\
\Pi_{t}=1.5, \sigma=1, \mu=5, \kappa=3, q=0.3\end{array}$} \\
\hline Date & Mean & Median & Mode \\
\hline$t+2$ & 1.8 & 1.8 & 1.8 \\
\hline$t+3$ & 2.8 & 2.3 & 1.9 \\
\hline$t+4$ & 3.5 & 2.8 & 2.0 \\
\hline$t+5$ & 3.9 & 3.3 & 2.2 \\
\hline$t+6$ & 4.2 & 3.8 & 2.4 \\
\hline$t+7$ & 4.5 & 4.2 & 2.7 \\
\hline$t+8$ & 4.6 & 4.4 & 3.6 \\
\hline$t+9$ & 4.7 & 4.6 & 4.6 \\
\hline$t+10$ & 4.8 & 4.7 & 4.8 \\
\hline$t+11$ & 4.9 & 4.8 & 4.9 \\
\hline Average & 4.0 & 3.7 & 3.1 \\
\hline
\end{tabular}

$$
E_{t} \pi_{t+1}=\Pi_{t}
$$

$$
\begin{aligned}
& E_{t} \pi_{t+1+i}= \\
& (1-q)^{i} \Pi_{t}+ \\
& q\left(\sum_{j=1}^{i}(1-q)^{j}\right)\left(\sum_{k \in R_{N}} \frac{\Pi_{k}}{N}\right) \quad i=1, \ldots, \infty
\end{aligned}
$$

The probability density of inflation one period ahead is given by equation (17), which is identical to equation (6). The probability densities of inflation more than one period ahead are given by equation (18), under the assumption of a diffuse prior distribution on the mean and standard deviation of inflation targets across regimes.

$$
f_{\pi_{t+1}}(x)=f_{\varepsilon}\left(x-\Pi_{t}\right)
$$

$$
\begin{aligned}
& f_{\pi_{t+1+i}}(x)= \\
& (1-q)^{i} f_{\varepsilon}\left(x-\Pi_{t}\right)+ \\
& q \sum_{j=1}^{i}(1-q)^{j-1} \frac{\int_{-\infty}^{\infty} \int_{-\infty}^{\infty} \int_{-\infty}^{\infty} f_{\varepsilon}(\varepsilon) f_{\eta}(x-\varepsilon) f_{\eta}\left(\Pi_{1}\right) \cdots f_{\eta}\left(\Pi_{N}\right) d \mu d \kappa d \varepsilon}{\left(\int_{-\infty}^{\infty} \int_{-\infty}^{\infty} f_{\eta}\left(\Pi_{1}\right) \cdots f_{\eta}\left(\Pi_{N}\right) d \mu d \kappa\right)} \\
& i=1, \ldots, \infty
\end{aligned}
$$




\section{Figure 5}

\section{Model 3}

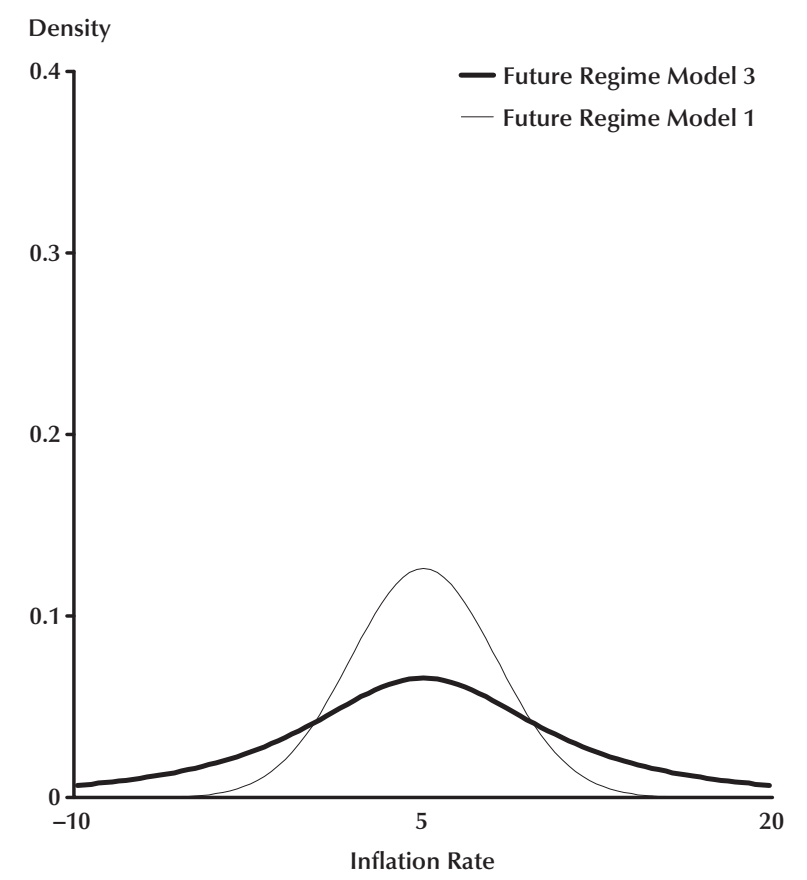

As the number of past regimes increases, this density approaches those of equations (7) and (8) and we return to the case of complete knowledge about the distribution of future inflation targets.

To illustrate the properties of this model, I need to specify values of current and past inflation targets. To continue with the flavor of past examples, I choose past inflation targets of 4.5 percent and 9 percent and a current inflation target of 1.5 percent. The average of these targets is 5 percent and the standard deviation is 3 percent. Thus, these outcomes are consistent with the earlier assumption of $\mu=5$ and $\kappa=3$. Figure 5 displays the density of future inflation under the assumption that there is a regime shift-that is, the ratio of the triple integral to the double integral in equation (18). For comparison, Figure 5 also displays the density of future inflation after a regime shift under the assumption of complete knowledge of the distribution of inflation targets, which was originally displayed in Figure 1. It is not surpris-

\section{Figure 6}

\section{Model 3}

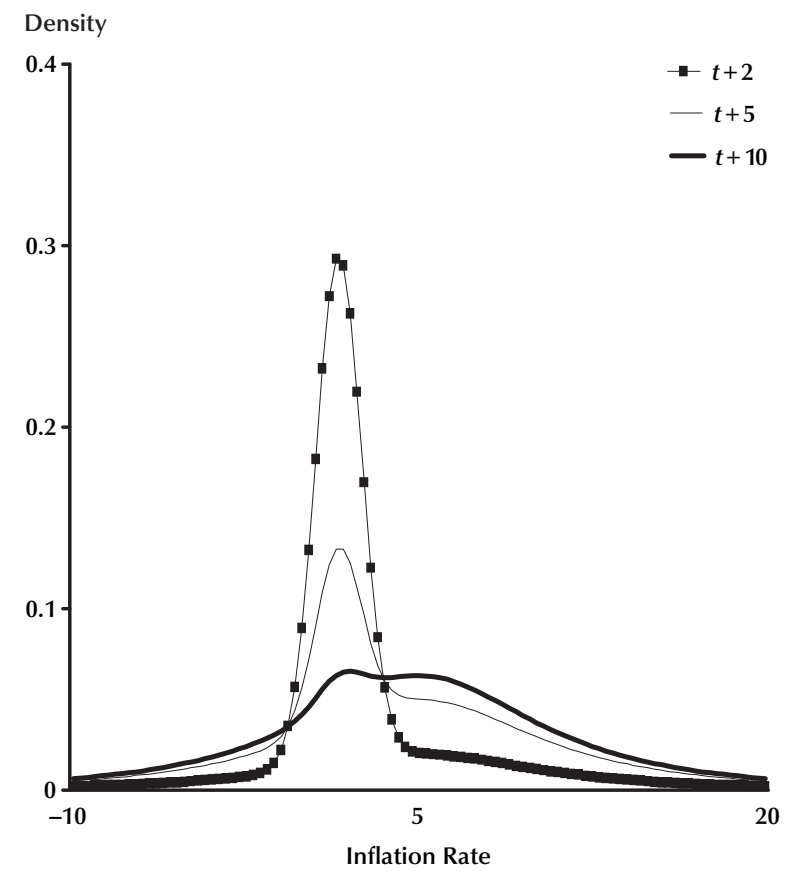

ing that the density without knowledge is more diffuse than the density with knowledge. Both densities are symmetric around the same mean, however, as a result of the choice of observed inflation targets with the same mean as the true distribution.

Figure 6 displays the densities of inflation in three specific future periods. Once again, the densities are asymmetric whenever there is a positive probability that a regime shift may affect inflation in the period in question. Table 4 , which pertains to Model 3, displays the mean, median, and mode of inflation in various future periods under the assumption that agents do not know the parameters of the distribution of future inflation targets and must infer them from observed inflation targets. The means and medians are identical to those displayed in Table 1 because the average of current and past inflation is assumed to be equal to the true mean of inflation targets across regimes. The only difference between Model 3 and Model 1 is that the density of infla- 
tion after a regime change is much more diffuse. This diffuseness affects the mode of future inflation because the secondary peak at 5 percent inflation is much lower than in Model 1. This

diffuseness has no effect on the mean or median of future inflation.

Finally, I consider the effect of a new regime on the mean of future inflation in the case of learning about the distribution of inflation targets. Suppose that a new regime occurs in the example above with an inflation target of 1.5 percent. In other words, suppose that a new central bank governor chose to continue the previous inflation target of 1.5 percent. The effect of this new regime depends on the number of previously observed regimes. If there were only three previous regimes, the average of current and past inflation targets drops from 5 percent to 4.1 percent. If there were ten previous regimes, which is the number of regimes estimated for Canada by $R R$, the average of current and past regimes declines by much less, from 5 percent to 4.7 percent. In other words, the effect of a given inflation regime on agents' expectations for future regimes is smaller when agents have experienced more changes in regimes in the past. Of course, it is possible that agents could draw inferences from regime changes that occurred before they were born-which might imply a very large number of past regimes-but in reality it is likely that trends in political systems and in financial technology may cause agents to heavily discount the relevance of regimes in the distant past.

\section{EMPIRICAL SUPPORT}

Estimation and testing of the models in the previous section pose a serious econometric challenge that is beyond the scope of this paper. Instead, I show that artificial data generated by the basic model of this paper behave in a manner similar to observed inflation and that this model may explain certain puzzling properties of the observed data. In addition, I show that the model developed here may be able to explain puzzling features of the evidence on long-run inflation expectations.

\section{Table 4}

\begin{tabular}{|c|c|c|c|}
\hline \multicolumn{4}{|c|}{$\begin{array}{l}\text { Asymmetric Distribution of Future } \\
\text { Rates: Model } 3 \\
\Pi_{R}=\{4.5,9,1.5\}, \Pi_{t}=1.5, \sigma=1, q=0.3\end{array}$} \\
\hline Date & Mean & Median & Mode \\
\hline$t+1$ & 1.5 & 1.5 & 1.5 \\
\hline$t+2$ & 2.5 & 1.9 & 1.5 \\
\hline$t+3$ & 3.3 & 2.4 & 1.5 \\
\hline$t+4$ & 3.8 & 3.1 & 1.6 \\
\hline$t+5$ & 4.2 & 3.6 & 1.7 \\
\hline$t+6$ & 4.4 & 4.1 & 1.7 \\
\hline$t+7$ & 4.6 & 4.4 & 1.7 \\
\hline$t+8$ & 4.7 & 4.6 & 1.8 \\
\hline$t+9$ & 4.8 & 4.7 & 1.9 \\
\hline$t+10$ & 4.9 & 4.8 & 2.0 \\
\hline Average & 3.9 & 3.5 & 1.6 \\
\hline
\end{tabular}

Despite the fact that this model does not incorporate any serial correlation of inflation within a regime, nor any serial correlation across regimes, it is capable of explaining much of the observed serial correlation of inflation. Over the sample period examined by RR, 1954-93, the Canadian CPI inflation rate has an estimated dominant autoregressive root of about 0.85 , and augmented Dickey-Fuller (ADF) tests cannot reject a unit root at any significance level. Monte Carlo data generated by Model 1 with the parameters in Table 1 for the same number of observations yield a median dominant autoregressive root of about 0.5; and ADF tests reject a unit root at the 5 percent level only about 45 percent of the time. If the model is extended to include an autoregressive lag on inflation of 0.7 (the mean of the within-regime autoregressive parameters estimated by RR) and new Monte Carlo data are generated, the median dominant root increases to 0.82 and the power of the 5 percent ADF test drops to 15 percent. For comparison, data generated by a simple autoregression with no regime shifts and a lag coefficient of 0.7 yield a median estimated dominant root of 0.66 and the power of the 5 percent ADF test is 40 percent.

In addition to explaining the near unit-root behavior of inflation over long horizons, a model 


\section{Gagnon}

with regime shifts can also explain the apparent stationarity of inflation over certain shorter horizons. Simply put, inflation is stationary within regimes; therefore, one ought to be able to reject nonstationarity in a regime that is sufficiently long-lasting. For example, ADF tests on quarterly U.S. inflation reject a unit root between 1954 and 1966 and also between 1984 and 1996. RR find that regimes of this length are plausible for the United States; using U.S. data, they estimate a probability of only 10 percent per year of a regime shift ( $q=0.10)$. Levin and Piger (2002) show that there is strong evidence of shifts in average inflation in many industrial countries and that allowing for such breaks leads to estimates of low persistence in inflation in most countries.

The asymmetric distribution of future inflation in these models of regime shifts may explain the asymmetric distribution of survey responses on future inflation expectations. Carlson (1975) and Lahiri and Teigland (1987) present evidence that the distribution of 1-year-ahead inflation expectations across survey respondents is usually asymmetrically distributed. Moreover, the direction of the skewness is identical to that predicted by a regime-shift model for the true distribution of future inflation. ${ }^{6}$ When inflation is higher than its historical average, expectations are skewed negatively. When inflation is lower than its historical average, expectations are skewed positively.

A more direct measure of the asymmetry of the distribution for future inflation is captured by the Survey of Professional Forecasters, which asks forecasters to provide a probability density for next year's inflation rate in the United States. ${ }^{7}$ Based on these densities, one can calculate the

\footnotetext{
${ }^{6}$ I am unaware of any research on how the distribution of a variable affects the distribution across individual forecasts of that variable. Nevertheless, these results are suggestive.

7 The Survey is conducted by the Federal Reserve Bank of Philadelphia; www.philadelphiafed.org/econ/spf/. Forecasters are asked to assign probabilities of inflation occurring in each of 10 buckets. The bucket widths are 1 percentage point, except for the bottom and top buckets, which are open-ended. I assigned a mid-point for the open-ended buckets equal to 1 percentage point away from the mid-point of the adjacent bucket. The probabilities attached to the open-ended buckets were very low. The Bank of England has asked a similar question in its Survey of External Forecasters since 1996, but its survey has fewer and more frequently changing density buckets.
}

mean, median, and mode of future inflation for each forecaster. ${ }^{8}$ Between 1992:Q1 and 2008:Q1, the average of the forecast means was 2.50 percent; the average of the forecast medians was 2.45 , and the average of the forecast modes was $2.43 .^{9}$ The differences between the average mean, median, and mode are not statistically significant. Nevertheless, they do follow the qualitative pattern one would expect if recent inflation is below its long-run average and agents are factoring in at least a small probability of a change in monetary policy regime. Moreover, this survey does not ask for the probability density of inflation beyond the next year. As we have seen, the impact of potential future regime changes on the probability distribution of inflation is greater for longer-term forecasts.

Finally, the asymmetric distribution of future inflation may explain the tendency for inflation compensation in bond yields to be larger than both the official inflation targets of central banks and surveys of long-run expected inflation from professional forecasters. The first column of Table 5 lists the inflation target or the center of the target range for countries that have announced a numeric goal for inflation. The second column lists average inflation expectations over the next 10 years from the October 8, 2007, Consensus Forecasts survey. ${ }^{10}$ The third column lists inflation compensation implied by the difference between 10-year nominal and inflation-indexed bond yields as of the same date. ${ }^{11}$ In every case but New Zealand, the survey response for longrun inflation is within 0.1 percent of the announced target. This result may reflect a relatively low perceived probability of a regime shift, leading to a forecast mode equal to the tar-

\footnotetext{
8 The mean is calculated as the probability of each bucket times the midpoint of that bucket summed over all buckets. The median is calculated by interpolating between the midpoints of the two buckets that have cumulative density on either side of 0.50 . The mode is calculated as the average of the midpoints of the three buckets with highest probability weighted by their respective probabilities.

9 Similar results were obtained for earlier years, but there were fewer buckets and the ranges changed over time, making the estimates much less precise.

${ }^{10}$ See www.consensusforecasts.com.

${ }^{11}$ Bond data were obtained from Bloomberg.
} 
get in the current regime. Interestingly, the sole exception, New Zealand, is also the only one of these countries to have experienced an announced change in the inflation target since an inflation goal was first publicly adopted. In every case but Japan, the inflation compensation in bond yields is greater than the policy target and, by extension, inflation compensation in bond yields is greater than inflation expectations in surveys. ${ }^{12}$ If survey respondents report the modal outcome and bondholders care about the average outcome, then the discrepancy between different measures of inflation expectations would be resolved. ${ }^{13,14}$

\section{INTERPRETATIONS AND EXTENSIONS}

The basic point of this paper is a stark one: Monetary regimes with inflation targets that are quite different from the average inflation rate across previous regimes may never be seen as fully credible over the long term by financial markets. Here I define credibility to be equality between the announced inflation target and the mean of the distribution of future inflation. This

\footnotetext{
${ }^{12}$ In the United Kingdom, inflation compensation in indexed bonds is tied to the retail price index. Retail price inflation has averaged about 0.5 percent higher than consumer price inflation, but, even after adjusting for this difference, inflation compensation in bond yields exceeds inflation expectations from surveys.

13 The professional forecasters surveyed in Consensus Forecasts presumably are judged by clients on the accuracy of their forecasts. I thank Jeff Dominitz for pointing out that forecasters should report the mean of future inflation if the penalty for forecast errors is proportional to the squared error. They should report something between the mean and the mode if the penalty is proportional to the absolute error. They should report the mode if the penalty is constant for all errors greater than a given magnitude and zero otherwise. In practice, forecasters communicate more to their clients than a simple point forecast. It is common to talk of the forecast being the most likely scenario with unequal upside and downside risks, which would imply a forecast that is closer to the mode than the mean. Boero, Smith, and Wallis (forthcoming) show that point forecasts of inflation in the United Kingdom since 1996 typically lie below the mean of the inflation densities supplied by the same forecasters.

${ }^{14}$ Two other factors to consider are inflation risk premiums and liquidity premiums. Aversion to inflation risk may account for some of the inflation compensation in nominal bond yields. But the lower liquidity of indexed bonds is an offsetting factor because it tends to push up yields on indexed bonds relative to yields on nominal bonds.
}

\section{Table 5}

10-Year Inflation Expectations (October 2007)

\begin{tabular}{lccc} 
& Policy & Survey & Bond \\
\hline Australia & 2.5 & 2.6 & 3.6 \\
Canada* $^{*}$ & 2.0 & 2.0 & 2.4 \\
Euro Area $^{\dagger}$ & 1.8 & 1.9 & 2.3 \\
Japan & 1.0 & 1.0 & 0.4 \\
New Zealand & 2.0 & 2.5 & 2.5 \\
Sweden & 2.0 & 1.9 & 2.5 \\
U.K. & 2.0 & 2.0 & 3.2 \\
U.S. & $\mathrm{N} / \mathrm{A}$ & 2.2 & 2.4
\end{tabular}

NOTE: *For Canada, bond measure is for 14-year maturity. †For the Euro Area, policy goal is inflation "close to but below 2 percent." * For the U.K., policy and survey refer to consumer prices whereas bonds are indexed to retail prices.

lack of credibility is not necessarily due to slow learning by private agents or to a lack of resolve on the part of the central bank. Even when agents understand and believe in the central bank's target inflation rate, they must attach some probability to a change in the regime. For example, the central bank governor may die or resign or the government may change the institutional framework of monetary policy. There is no way to guarantee that these things will not happen.

The key to credibility over the long term is the expected value of inflation under the next regime. This paper considers two approaches to modeling expectations of inflation under the next regime. In the first approach, it is assumed that agents know the constant mean inflation rate across regimes. If the current regime's inflation target is equal to this long-run inflation mean, then policy is credible in the long run. If the current regime's inflation target is far from the long-run inflation mean, then policy is not credible and policy will never become fully credible no matter how long the current regime lasts or how often similar regimes arise. In the second approach, agents update their expectations about inflation in the next regime based on inflation in the current and previous regimes. Under this approach, a sequence of low (or high) inflation regimes would change agents' expectations of inflation 


\section{Gagnon}

in the next regime. However, as demonstrated in a simple example, significant changes in long-run inflation expectations may still require a great deal of time.

One plausible extension of these models is to consider learning on the part of the central bank. For example, one may argue that the high inflation of the 1970s was a mistake, that central banks have learned their lessons, and that the public understands that this episode will not recur. Under this hypothesis, agents ought to place more weight on recent inflation rates when forming expectations about inflation in the next regime; in this case, long-run credibility would be easier to obtain than in the basic models. Nevertheless, as long as agents place some positive weight on past inflation targets in forming expectations about future inflation targets, the credibility problem will remain.

Another extension of the model would be to consider variation over time in the probability of a regime shift. One way to increase the long-run credibility of the current inflation target is to take steps to reduce the probability of a regime shift. Recent attempts in many countries to increase the independence of the central bank may be interpreted as reducing the probability of a regime shift and thus strengthening credibility. Nevertheless, it is not possible to guarantee that any regime will last forever.

Although the hypothesis of central bank learning seems plausible and many central banks have achieved greater independence in recent years, I would like to conclude the paper by noting several caveats. First, the recent recurrence of inflation in some countries that have a long history of inflation (such as Argentina and Venezuela) argues for caution about the idea that a bad experience with inflation inoculates a country against future inflation. At the very least, one should keep in mind that lessons learned may become lessons forgotten. Second, even if central banks have learned their lessons well and permanently, the public may be skeptical and the time needed to convince the public may be measured in decades rather than years. Third, even if one does discount the possibility of a return to doubledigit inflation, it is harder to justify ignoring the possibility of a return to moderate inflation rates of around 5 percent or so. In light of the fact that no one is recommending a regime with negative inflation rates, an inflation target that is very close to zero can never be credible in the long run, as long as there is some possibility of a return to positive inflation.

\section{REFERENCES}

Ammer, John and Freeman, Richard T. "Inflation Targeting in the 1990s: The Experiences of New Zealand, Canada, and the United Kingdom.” Journal of Economics and Business, May 1995, 47(2), pp. 165-92.

Bai, Jushan and Perron, Pierre. "Estimating and Testing Linear Models with Multiple Structural Changes.” Econometrica, January 1998, 66(1), pp. 47-78.

Baillie, Richard T.; Chung, Ching-Fan and Tieslau, Margie A. "Analysing Inflation by the Fractionally Integrated ARFIMA-GARCH Model.” Journal of Applied Econometrics, January-February 1996, 11(1), pp. 23-40.

Boero, Gianna; Smith, Jeremy and Wallis, Kenneth. "Uncertainty and Disagreement in Economic Prediction: The Bank of England Survey of External Forecasters.” Forthcoming in Economic Journal.

Carlson, John A. "Are Price Expectations Normally Distributed?" Journal of the American Statistical Association, December 1975, 70(352), pp. 749-54.

Chapman, David A. and Ogaki, Masao. "Cotrending and the Stationarity of the Real Interest Rate." Economics Letters, 1993, 42(2-3), pp. 133-38.

Evans, Martin D.D. and Lewis, Karen K. "Do Expected Shifts in Inflation Affect Estimates of the Long-Run Fisher Relation?” Journal of Finance, April 1995, 50(1), pp. 225-53.

Freeman, Richard T. and Willis, Jonathan L. "Targeting Inflation in the 1990s: Recent Challenges." International Finance Discussion Paper No. 525, Board of Governors of the Federal Reserve System, September 1995. 
Fuhrer, Jeffrey C. "Monetary Policy Shifts and LongTerm Interest Rates." Quarterly Journal of

Economics, November 1996, 111(4), pp. 1183-209.

Gagnon, Joseph E. "Long Memory in Inflation Expectations: Evidence from International Financial Markets." International Finance Discussion Paper No. 538, Board of Governors of the Federal Reserve System, February 1996.

Hassler, Uwe and Wolters, Jurgen. "Long Memory in Inflation Rates: International Evidence.” Journal of Business and Economic Statistics, January 1995, 13(1), pp. 37-45.

Hostland, Doug. "Changes in the Inflation Process in Canada: Evidence and Implications." Working Paper No. 95-5, Bank of Canada, May 1995.

Lahiri, Kajal and Teigland, Christie. "On the Normality of Probability Distributions of Inflation and GNP Forecasts." International Journal of Forecasting, 1997, 3, pp. 269-79.

Levin, Andrew and Piger, Jeremy. "Is Inflation Persistence Intrinsic in Industrial Countries?" Working Paper 2002-023E, Federal Reserve Bank of St. Louis, 2002.

Mishkin, Frederic S. "Is the Fisher Effect for Real? A Reexamination of the Relationship Between Inflation and Interest Rates." Journal of Monetary Economics, November 1992, 30(2), pp. 195-215.

Reserve Bank of New Zealand. Policy Targets Agreement. December 1996.

Ricketts, Nicholas and Rose, David. "Inflation, Learning and Monetary Policy Regimes in the G-7 Economies." Working Paper No. 95-6, Bank of Canada, June 1995.

Rose, Andrew. "Is the Real Interest Rate Stable?" Journal of Finance, December 1988, 43(5), pp. 1095-112.

Simon, John. "A Markov-Switching Model of Inflation in Australia." Research Discussion Paper No. 9611, Reserve Bank of Australia, December 1996. 
